\title{
Sleep disturbance among frontline nurses during the COVID-19 pandemic
}

\author{
Mohammed Al Maqbali ${ }^{1,2}$
}

Received: 30 October 2020 / Accepted: 18 June 2021 / Published online: 1 July 2021

(c) The Author(s) 2021

\begin{abstract}
The main objective of this study is to assess the prevalence of sleep disturbance and related psychological factors (stress, anxiety and depression) among frontline nurses in Oman during the COVID-19 pandemic. A cross-sectional and descriptive correlational design using Qualtrics ${ }^{\circledR}$ software was used in this research. Data were collected using the Pittsburgh Sleep Quality Index (PSQI), the Hospital Anxiety and Depression Scale (HADS) and the Perceived Stress Scale (PSS). Logistic regression was performed to identify factors associated with poor sleep quality. Of the 987 frontline nurses who participated, 58.8\% ( $n=580)$ reported poor sleep quality. In an examination of PSQI components the mean sleep duration was 7.04 $(\mathrm{SD}=1.59)$ hours per night, and the sleep latency mean was $38.18 \mathrm{~min}(\mathrm{SD}=31.81)$. Poor sleep $(p<.05)$ was significantly associated with age, marital status, years of experience, comorbidity, and whether family members or relatives were suspected or confirmed with having COVID-19. Logistic regression showed that poor quality of sleep was significantly associated with stress, anxiety and depression symptoms. Sleep disturbance is a significant problem for frontline nurses working in Oman during the COVID-19 pandemic. Appropriate interventions to maintain the health conditions and reduce sleep disturbance among frontline nurses are needed in order to help support nurses' work during contagious disease outbreaks. These can be implemented through online workshops and training to enhance nurses' responses to the pandemic or to any further disease outbreaks.
\end{abstract}

Keywords COVID-19 $\cdot$ Frontline nurses · Sleep disturbance $\cdot$ PSQI $\cdot$ Stress $\cdot$ Anxiety $\cdot$ Depression

\section{Introduction}

Severe acute respiratory syndrome coronavirus was identified at the end of December 2019 in Wuhan City, Hubei province, China, and has since spread worldwide [1]. On 11 February 2020, the World Health Organization (WHO) renamed the disease as the Corona Virus Disease-2019 (COVID-19) [2]. COVID-19 seriously threatens human health as it can be transmitted via close human-to-human contact. On 30th January 2020, a public health emergency was declared by the WHO, naming COVID-19 a pandemic [3]. As of 31st May 2021, a total of more than 170 million

Mohammed Al Maqbali

mhamedan@hotmail.com

1 Department of Nursing Midwifery and Health, Northumbria University, Newcastle-Upon-Tyne, UK

2 Al Buraimi Hospital Ministry of Health, Al Buraimi, Oman cases have been confirmed worldwide, with more than 3.5 million deaths [4].

This extreme number of patients can overwhelm healthcare systems with thousands of patients needing urgent care. This increases the workload on healthcare workers, especially frontline nurses who are in direct contact with patients with COVID-19. In June 2020, the International Council of Nurses (ICN) estimated that more than 600 nurses worldwide have died from COVID-19 [5]. Therefore, frontline nurses working in situations with a high risk of infection from patients can lead to sleep disturbance, stress, anxiety and depression.

Previous studies have reported the prevalence of sleep disturbance outcomes among healthcare workers during SARS and Middle East Respiratory Syndrome (MERS) outbreaks [6-8]. Healthcare workers, particularly nurses, are at high risk of being infected because they are in the closest proximity to patients. Current research has already shown that Chinese nurses are suffering from sleep disturbance due to the COVID-19 pandemic [9]. 
However, to date, little has been known about the impact of the COVID-19 outbreak on the incidence of sleep disturbance among frontline nurses. This study will help to clarify the sleep disturbance status of frontline nurses, knowledge of which is crucial to better controlling and planning for dealing with COVID-19 or similar diseases in the future. The aim of this study is to assess the prevalence of sleep disturbance and related psychological factors (stress, anxiety and depression) among frontline nurses in Oman during the COVID-19 pandemic.

\section{Methods}

\section{Study design}

The study employed a large-scale cross-sectional, descriptive correlational design. The survey was developed using the Qualtrics ${ }^{\circledR}$ online platform. Participants were invited to complete the questionnaire through a link which was sent by social media.

\section{Setting and sampling}

The participants were recruited from all Ministry of Health institutions in Oman. The study was performed from 7th August 2020 to 30th August 2020. The inclusion criteria for participating in the study were: being a nurse who worked in a Ministry of Health institution; being aged older than 18 years; and being frontline nurses (in contact with confirmed or suspected COVID-19 patients in the workplace). Exclusion criteria included a history of psychiatric or neurological disorders that could interfere with participation in the study, and nurses who do not have any working contact with COVID-19 patients.

\section{Measures}

The questionnaire included detailed demographics, background history and psychometric scales including the Pittsburgh Sleep Quality Index (PSQI), the Hospital Anxiety and Depression Scale (HADS) and the Perceived Stress Scale (PSS).

\section{Demographics}

Information about the participants' age, sex, marital status, years of experience, types of institution (hospital or primary setting) and comorbidities were obtained in the survey. In addition, participants were asked the three following questions: (1) Do you have confirmed COVID-19? (Yes/No) (2) Do any family members have suspected or confirmed COVID-19? (Yes/No) (3) Do you come into contact with confirmed or suspected COVID-19 patients in your workplace? (Yes/No).

\section{Sleep disturbance scale}

The PSQI self-rated questionnaire assesses sleep quality over the past month [10]. The PSQI is a 19-item instrument that is categorised into seven components: subjective sleep quality, sleep latency, sleep duration, habitual sleep efficiency, sleep disturbances, use of sleep medications and daytime dysfunction. The score for each of the seven components can range from 0 to 3 . The PSQI global score is calculated by summing the seven components, which a possible range from 0 to 21 , with a global score of $\geq 6$ indicating poor sleep quality in the previous month. The PSQI has acceptable reliability in Arabic (Cronbach's $\alpha=0.77$ ) [11].

\section{Stress scale}

The PSS [12], a self-administered questionnaire, was used to measure post-traumatic stress disorder (PTSD). The PSS consisted of 10 items; each item response ranged from 0 (never) to 4 (very often), with scores ranging from 0 to 40 for the total score of the scale. Scores $\geq 14$ indicate the presence of stress [13]. The PSS revealed an internal consistency of 0.90 [14].

\section{Depression and anxiety scale}

The HADS includes 14 items assessing anxiety ( 7 items) and depression ( 7 items). These are rated using a 4-point Likerttype response (from 0 to 3) [15]. The scores in each subscale are computed by summing the corresponding items, with a maximum score of 21 for each subscale. The recommended cut-off values are $\geq 8$ for both anxiety and depression [16]. The HADS showed very good internal consistency (Cronbach's $\alpha=0.83$ ) [17].

\section{Data analysis}

The data were entered into the Statistical Package for Social Sciences (SPSS) version 25. To address the research questions, descriptive statistics were calculated in the form of means, standard deviations, standard errors, frequencies, and percentages with regard to all the scales, subscales and participant variables. Chi-square (or Fisher's exact test) was used to compare good and poor sleeper groups in terms of demography and stress, anxiety, and depression.

Logistic regression analyses with a full entry model were used to identify independent factors (age, sex, marital status, years of experience, type of institution (i.e., hospital or primary care), confirmed with COVID-19, family member with suspected or confirmed COVID-19, stress, anxiety, and 
depression) to determinants of poor sleepers (global PSQI score $\geq 6$ ). Odds ratios (OR) and $95 \%$ confidence intervals (CI) are reported. The $p>0.05$ was considered to be statistically significant for all analyses.

\section{Ethical considerations}

Ethical permission was sought from Ministry of Health in Oman (MoH/CSR/20/23761). The confidentiality and privacy of the participants were maintained. A consent statement was obtained from all participants as it was presented on the first screen of the survey tool (Table 1).

\section{Results}

A total of 987 valid questionnaires were finally received through the use of the online survey. The majority of the frontline nurses were female $(90.7 \%, n=895)$, and were married $(85 \%, n=839)$. The largest age group was those aged $31-40$ years $(59.5 \%, n=587)$, followed by $41-50$ years $(20.1 \%, n=198)$. Approximately two-thirds of the participants were working in a hospital setting $(73.3 \%, n=723)$. Around $30 \%$ of the participants had 6-10 years of experience. Only $15.1 \%$ of the participants were diagnosed with a chronic disease. Around one-quarter of the frontline nurses had confirmed or suspected COVID-19 within their family or among relatives $(24.5 \%, n=242)$. Seventy-one of the participants $(7.2 \%)$ were confirmed to have contracted COVID-19.

In the total group, the mean of sleep disturbance was 6.96 (SD. 3.97, 0-21). Of the 987 participants, 580 (58.8\%) experienced poor sleep quality, and $407(41.2 \%)$ considered themselves to be good sleepers. As shown in Fig. 1, the PSQI component mean score revealed that sleep efficiency displayed the lowest score $(M=0.28, \mathrm{SD}=0.65)$ indicating relatively good sleep, whereas the worse component, sleep latency, displayed the highest score $(M=1.65, \mathrm{SD}=0.97)$.

An examination of individual PSQI and component scores revealed that the average sleep duration was 7.04 $(\mathrm{SD}=1.59)$ hours per night with $61.3 \%(n=605)$ of participants reporting sleep of less than $7 \mathrm{~h}$. The mean of sleep latency was $38 \mathrm{~min}$, with $71.4 \%(n=705)$ of the participants reporting more than $15 \mathrm{~min}$. Almost one-quarter $(23.7 \%)$ of the participants reported a sleep efficiency of less than $85 \%$. Thirty percent of the participants rated their quality of sleep as "fairly bad" or "very bad". The two most common reasons for sleep disturbance was "could not get to sleep within 30 min", and "waking up in the middle of the night or early morning" as reported by $56.03 \%$ and $54.31 \%$, respectively (see Table 2). A considerable proportion of the frontline nurses had symptoms of stress $(77.4 \%, n=764)$, anxiety $(47.6 \%, n=470)$, and depression $(42.2 \%, n=417)$.

There were differences in reports of poor sleep among those aged between 18 and 30 (20\% vs. $13.3 \%$ ), single individuals $(16.2 \%$ vs. $8.6 \%$ ), Others (widowed or divorced or separated) $(2.4 \%$ vs. $1.2 \%)$, working in primary healthcare ( $29 \%$ vs. $23.6 \%)$, nurses with $6-10(31.2 \%$ vs. $28.3 \%)$ and those with $15-20(20.7 \%$ vs. $13.8 \%)$ years of experience, those with chronic diseases (18.4\% vs. $10.3 \%)$, and those with family members with suspected or confirmed COVID19 ( $28.6 \%$ vs. $18.7 \%)(p<0.05)$ compared to good sleepers.

Poor sleep was more prevalent among nurse with stress ( $90.2 \%$ vs. $59.2 \%, p<0.001)$, anxiety $(61.7 \%$ vs. $27.5 \%$, $p<0.001)$, and depression $(53.6 \%$ vs. $26 \%, p<0.001)$, when compared with the good sleeper group.
Fig. 1 Mean of Pittsburgh Sleep Quality Index (PSQI) Components

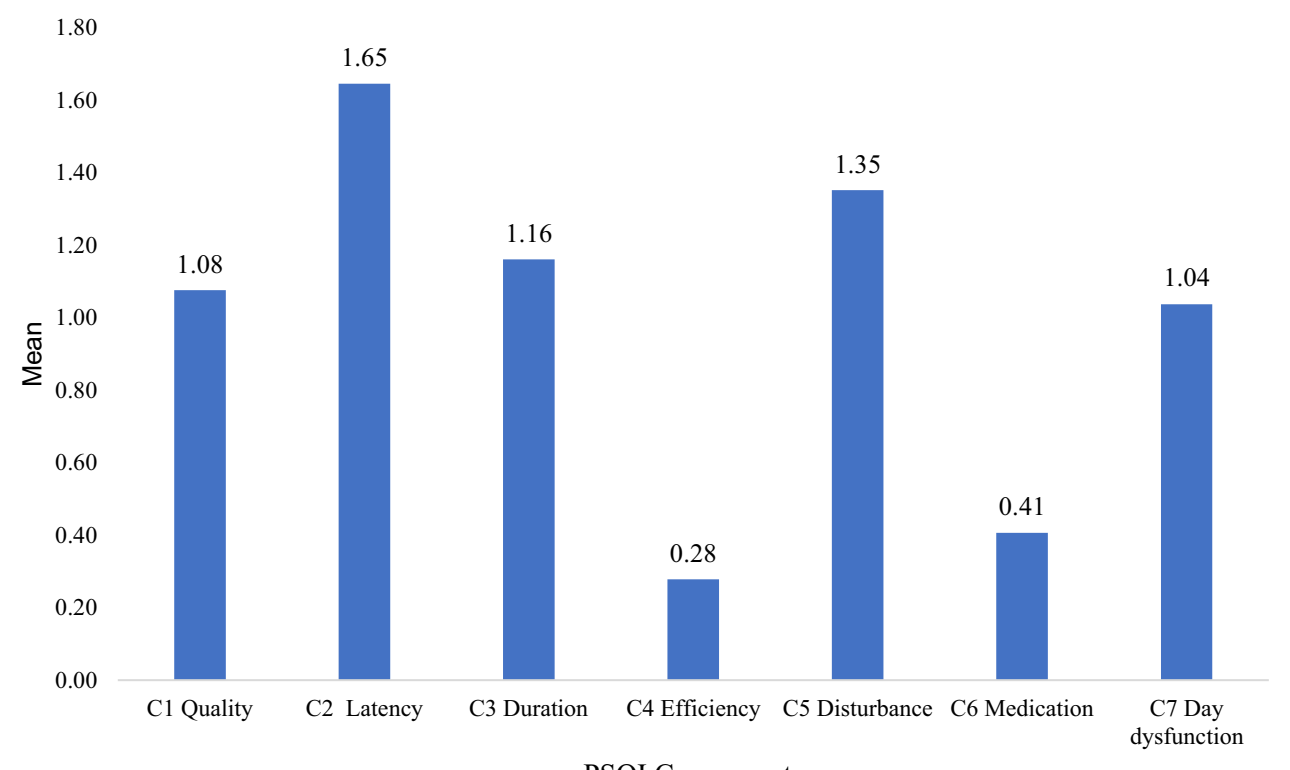

PSQI Components 
Table 1 Demographic and clinical characteristic of participants $(n=987)$

\begin{tabular}{|c|c|c|c|c|c|c|c|}
\hline & \multirow[t]{2}{*}{$\mathrm{n}$} & \multirow[t]{2}{*}{$\%$} & \multicolumn{2}{|c|}{$\begin{array}{l}\text { Good sleeper } \\
(n=407, \\
41.2 \%)\end{array}$} & \multicolumn{2}{|c|}{$\begin{array}{l}\text { Poor sleeper } \\
(n=580, \\
58.8 \%)\end{array}$} & \multirow[t]{2}{*}{$p$} \\
\hline & & & $\mathrm{n}$ & $\%$ & $\mathrm{n}$ & $\%$ & \\
\hline Gender & & & & & & & .98 \\
\hline Male & 92 & 9.3 & 38 & 9.3 & 54 & 9.3 & \\
\hline Female & 895 & 90.7 & 369 & 90.7 & 526 & 90.7 & \\
\hline Age & & & & & & & .004 \\
\hline $18-30$ & 170 & 17.2 & 54 & 13.3 & 116 & 20 & \\
\hline $31-40$ & 587 & 59.5 & 245 & 60.2 & 342 & 59 & \\
\hline $41-50$ & 198 & 20.1 & 88 & 21.6 & 110 & 19 & \\
\hline More than 50 & 32 & 3.2 & 20 & 4.9 & 12 & 2.1 & \\
\hline Marital status & & & & & & & .001 \\
\hline Married & 839 & 85.0 & 367 & 90.2 & 472 & 81.4 & \\
\hline Single & 129 & 13.1 & 35 & 8.6 & 94 & 16.2 & \\
\hline Others & 19 & 1.9 & 5 & 1.2 & 14 & 2.4 & \\
\hline Working in & & & & & & & .06 \\
\hline Hospitals & 723 & 73.3 & 311 & 76.4 & 412 & 71 & \\
\hline Primary Health Care & 264 & 26.7 & 96 & 23.6 & 168 & 29 & \\
\hline Years of experience & & & & & & & .02 \\
\hline$<2$ & 99 & 10.0 & 47 & 11.5 & 52 & 9 & \\
\hline $3-5$ & 137 & 13.9 & 68 & 16.7 & 69 & 11.9 & \\
\hline $6-10$ & 296 & 30.0 & 115 & 28.3 & 181 & 31.2 & \\
\hline $11-15$ & 195 & 19.8 & 84 & 20.6 & 111 & 19.1 & \\
\hline $16-20$ & 176 & 17.8 & 56 & 13.8 & 120 & 20.7 & \\
\hline$>20$ & 84 & 8.5 & 37 & 9.1 & 47 & 8.1 & \\
\hline Comorbidities & & & & & & & .00 \\
\hline Yes & 149 & 15.1 & 42 & 10.3 & 107 & 18.4 & \\
\hline None & 838 & 84.9 & 365 & 89.7 & 473 & 81.6 & \\
\hline Families or relatives suspected or confirmed & & & & & & & .00 \\
\hline Yes & 242 & 24.5 & 76 & 18.7 & 166 & 28.6 & \\
\hline No & 745 & 75.5 & 331 & 81.3 & 414 & 71.4 & \\
\hline Are you confirmed of COVID-19 & & & & & & & .80 \\
\hline Yes & 71 & 7.2 & 28 & 6.9 & 43 & 7.4 & \\
\hline No & 916 & 92.8 & 379 & 93.1 & 537 & 92.6 & \\
\hline PSS & & & & & & & .00 \\
\hline No Stress (PSS < 14) & 223 & 22.6 & 166 & 40.8 & 57 & 9.8 & \\
\hline Stress $(\mathrm{PSS} \geq 14)$ & 764 & 77.4 & 241 & 59.2 & 523 & 90.2 & \\
\hline HADS anxiety & & & & & & & .00 \\
\hline No anxiety $(\operatorname{HADS}(\mathrm{A})<8)$ & 517 & 52.4 & 295 & 72.5 & 222 & 38.3 & \\
\hline Anxiety (HADS(A) $\geq 8$ ) & 470 & 47.6 & 112 & 27.5 & 358 & 61.7 & \\
\hline HADS depression & & & & & & & .00 \\
\hline No depression $(\operatorname{HADS}(\mathrm{D})<8)$ & 570 & 57.8 & 301 & 74 & 269 & 46.4 & \\
\hline Depression $(\mathrm{HADS}(\mathrm{D}) \geq 8)$ & 417 & 42.2 & 106 & 26 & 311 & 53.6 & \\
\hline
\end{tabular}

All the variables were selected to form a logistic regression model. The result was statistically significant, $\chi^{2}$ (19, $n=987)=228.6, p<0.001$, which indicated that the model was able to identify effects of independent variables. The model explained between $20.7 \%$ (Cox and Snell R square) and $27.9 \%$ (Nagelkerke $\mathrm{R}$ square) of the variance of the independent variables. The overall correction prediction was $71 \%$. The Hosmer-Lemeshow test supported the model $\left(\chi^{2}=7.66, p=0.467\right)$.

The result of the logistic regression analyses showed that none of the independent variables (gender, institution type, those with chronic diseases, family member with 
Table 2 Reason for sleep disturbance

\begin{tabular}{lll}
\hline Reason & \multicolumn{2}{l}{$\geq 1$ times/Week } \\
\cline { 2 - 3 } & $\mathrm{n}$ & $\%$ \\
\hline Cannot get to sleep within 30 min & 553 & 56.03 \\
Wake up middle or early Morning & 536 & 54.31 \\
Use bathroom & 486 & 49.24 \\
Too hot & 379 & 38.4 \\
Pain & 346 & 35.06 \\
Bad dreams & 263 & 26.65 \\
Too cold & 169 & 17.12 \\
Cannot breathe comfortably & 157 & 15.91 \\
Cough or snore loudly & 152 & 15.4 \\
\hline
\end{tabular}

suspected or confirmed COVID-19, and participants with confirmed COVID-19) had significant effects on poor sleep (Table 3). Stress was the strongest factor affecting poor sleep

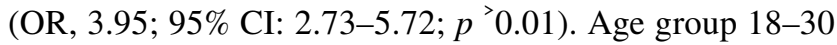
appeared to be the second factor affecting poor sleep (OR, 3.52; 95\% CI: $1.17-10.54 ; p=0.02)$. The models showed that single marital status, less than two years and between three and five years' experience, with anxiety and depression, were significant factors of poor sleep.

\section{Discussion}

This study finds that sleep is frequently problematic for frontline nurses during the COVID-19 pandemic. The main finding from this study demonstrated that almost three-fifths (58.8\%) of the frontline nurses had poor sleep quality, which was much higher than the $20-39 \%$ found during ordinary times [18, 19]. In addition, $77.4 \%, 47.6 \%$ and $42.2 \%$, of frontline nurse had stress, anxiety, and depression.

These results were higher than a previous study from China, which reported an incidence of $38 \%$ poor sleep in the case of frontline nurses exposed to COVID-19 [20], whereas another study conducted in Italy found that only $11 \%$ of nurses had reported poor quality sleep during the COVID-19 pandemic [21]. In a recent systematic review and meta-analysis of 18 studies involving 10,697 nurses, Al Maqbali et al., [22]found the prevalence of sleep disturbance $43 \%$, and studies included in the review reported varied prevalence of sleep disturbance between $12 \%$ and $87 \%$ during the COVID-19 pandemic.

In comparison with the general population, the current study findings were that the incidence of poor sleep was higher. For example in France it was 19.1\% [23], in China $24.6 \%$ [24], and in Italy (42.2\%) [25]. This difference may be partially explained by the different isolation measures that were applied by countries in their attempts to reduce the spread of COVID-19. In addition, differences
Table 3 Logistic regression analyses of factors associated with poor sleep quality odds ratio $(95 \% \mathrm{CI})$

\begin{tabular}{|c|c|c|c|}
\hline Variables & OR & $95 \% \mathrm{CI}$ & $P$ \\
\hline \multicolumn{4}{|l|}{ Gender } \\
\hline Male & Ref & & \\
\hline Female & 1.08 & $0.66-1.78$ & .76 \\
\hline \multicolumn{4}{|l|}{ Age } \\
\hline More than 50 & Ref & & \\
\hline $18-30$ & 3.52 & $1.17-10.54$ & .02 \\
\hline $31-40$ & 2.47 & $0.92-6.63$ & .07 \\
\hline $41-50$ & 2.37 & $0.93-6.02$ & .07 \\
\hline \multicolumn{4}{|l|}{ Marital status } \\
\hline Married & Ref & & \\
\hline Single & 1.96 & $1.21-3.20$ & .01 \\
\hline Others & 2.64 & $0.75-9.3$ & .13 \\
\hline \multicolumn{4}{|l|}{ Working In } \\
\hline Primary Health Care & Ref & & \\
\hline Hospitals & 0.97 & $0.69-1.3$ & .84 \\
\hline \multicolumn{4}{|l|}{ Years of experience } \\
\hline$>20$ & Ref & & \\
\hline$<2$ & 0.40 & $0.17-0.97$ & .04 \\
\hline $3-5$ & 0.45 & $0.21-0.98$ & .04 \\
\hline $6-10$ & 0.90 & $0.45-1.81$ & .77 \\
\hline $11-15$ & 0.79 & $0.40-1.57$ & .51 \\
\hline $16-20$ & 1.17 & $0.59-2.31$ & .65 \\
\hline \multicolumn{4}{|l|}{ Comorbidities } \\
\hline Yes & Ref & & \\
\hline None & 1.42 & $0.92-2.19$ & .11 \\
\hline \multicolumn{4}{|c|}{ Families or relatives suspected or confirmed } \\
\hline No & Ref & & \\
\hline Yes & 1.09 & $0.75-1.58$ & .66 \\
\hline \multicolumn{4}{|l|}{ Are you confirmed of COVID-19 } \\
\hline No & Ref & & \\
\hline Yes & 1.06 & $0.58-1.92$ & .86 \\
\hline \multicolumn{4}{|l|}{ PSS } \\
\hline No stress (PSS < 14) & Ref & & \\
\hline Stress (PSS $\geq 14)$ & 3.95 & $2.73-5.72$ & .001 \\
\hline \multicolumn{4}{|l|}{ HADS anxiety } \\
\hline No anxiety (HADS $(\mathrm{A})<8$ ) & Ref & & \\
\hline Anxiety $(\operatorname{HADS}(\mathrm{A}) \geq 8)$ & 2.27 & $1.62-3.17$ & .001 \\
\hline \multicolumn{4}{|l|}{ HADS depression } \\
\hline No depression $(\operatorname{HADS}(\mathrm{D})<8)$ & Ref & & \\
\hline Depression (HADS(D) $\geq 8)$ & 1.48 & $1.05-2.07$ & .02 \\
\hline
\end{tabular}

in cultural norms, beliefs and values between countries may affect the prevalence of sleep disturbance. Another possible reasons for the differences are the timing of data collection and the instruments (cut-off) used. In addition, this study was conducted in August 2020 and the peak period of the COIVD-19 outbreak in Oman was July 2020, 
which might have increased the associated factors of sleep disturbance, stress, anxiety and depression.

In this study, $61.3 \%$ of the participants slept less than $7 \mathrm{~h}$. These result were high compared to a study conducted by Ahmed et al., [26] which involved 2,095 of the general Arab population which found that $33.8 \%$ of the respondents were slept for a relatively short period $(<7 \mathrm{~h})$. However, the National Sleep Foundation recommended at least $7-9 \mathrm{~h}$ of sleep per day for adults [27]. In fact, $60 \%$ of the participants in this study were awake before 6:30 am. Most of the nurses in our study sample were Muslim. Given that that are required to pray five times a day, the first prayer (Fajr) being one-one and a half hours before sunrise, this may the reason why most of the participants were awake before $6 \mathrm{am}$.

In addition, the results suggest that sleep latency found using the PSQI was the most disturbing component having the highest mean score compared to the other six components with an average of $38 \mathrm{~min}$. Schutte-Rodin et al. [28] suggested that taking more than $30 \mathrm{~min}$ to fall asleep can be considered to be evidence of insomnia. This study found that the poor sleep quality of frontline nurses was attributed to such aspects as insomnia, early morning wakening, and being too hot or cold. This is consistent with previous studies which found an association between pain [29], early morning awakening [30], being too hot or cold [31] and disturbance of sleep among nurses.

The present study indicates that frontline nurses with at least one chronic disease had the highest levels of sleep disturbance. This may be because comorbidities are highly prevalent among fatal cases of COVID-19 [32, 33]. The present study demonstrates that age between 18 and 30 , being single, and having less than 5 years' experience were predicators of poor sleep. Several researchers have suggested that a lack of skills, knowledge and experience may have an influence on the increased prevalence of sleep disturbance among nurses under 35 years of age [34-36].

In the current study, a significant association was found between poor sleep and stress, anxiety, and depression. Likewise, the risk of being stressed, anxious, and depressed significantly predicted the poor sleep quality. A similar result was reported by Lai et al., [20], Yin et al., [37] and Shechter et al. [38], among nurses during the COVID-19 pandemic. Understanding the underlying causes of sleep disturbance is essential with regard to introducing interventions that can help to reduce the symptoms of frontline nurses during a pandemic.

The study has a number of limitations. First, the study utilized a cross-sectional design; therefore, it represents the evaluation of stress, anxiety, depression and poor sleep disturbance at one point in time, without any longitudinal observation of the participants. Second, the participants were recruited from Oman, which may limit generalization to other countries. Finally, the study relied on the use of self-reporting questionnaires to assess the extent of sleep disturbance; however, this may differ from an objective sleep assessment [39].

\section{Conclusion}

Sleep disturbance is a significant problem for frontline nurses treating patient with COVID-19 in Oman. Sleep disturbance is significantly related to increases in stress, anxiety, and depression in terms of the participating group. This study helps to improve understanding of the sleep disturbance of frontline nurses exposed to an outbreak of a fastspreading, life-threatening infectious disease, and could help strengthen preparations for responding to possible future outbreaks or infectious disease pandemics. Furthermore, it provides a solid foundation for the next step in the research, which aims to identify appropriate interventions to improve the sleep quality and psychological wellbeing of frontline nurses.

Acknowledgements I certify that there is no actual or potential conflict of interest in relation to this article.

Authors' contributions AM: Conceptualization, Methodology, Investigation, Data curation, Software, Formal analysis, Writing-original draft, Writing-review and editing.

Open Access This article is licensed under a Creative Commons Attribution 4.0 International License, which permits use, sharing, adaptation, distribution and reproduction in any medium or format, as long as you give appropriate credit to the original author(s) and the source, provide a link to the Creative Commons licence, and indicate if changes were made. The images or other third party material in this article are included in the article's Creative Commons licence, unless indicated otherwise in a credit line to the material. If material is not included in the article's Creative Commons licence and your intended use is not permitted by statutory regulation or exceeds the permitted use, you will need to obtain permission directly from the copyright holder. To view a copy of this licence, visit http://creativecommons.org/licenses/by/4.0/.

\section{References}

1. Li Q, Guan X, Wu P, Wang X, Zhou L, Tong Y, et al. Early Transmission Dynamics in Wuhan, China, of novel coronavirusinfected pneumonia. N Engl J Med. 2020;382:1199-207.

2. WHO. Naming the coronavirus disease (COVID-19). 2020. https://www.who.int/emergencies/diseases/novel-coronavirus2019/technical-guidance/naming-the-coronavirus-disease-(covid2019)-and-the-virus-that-causes-it. Accessed 12 Sept 2020.

3. WHO. International Health Regulations Emergency Committee on novel coronavirus in China. 2020. https://www.who.int/ news-room/events/detail/2020/01/30/default-calendar/internatio nal-health-regulations-emergency-committee-on-novel-coronavirus-in-china. Accessed 12 Sept 2020.

4. WHO Coronavirus (COVID-19) Dashboard. 2021. https://covid 19.who.int. Accessed 1 June 2021. 
5. ICN. More than 600 nurses die from COVID-19 worldwide [Internet]. ICN - Int. Counc. Nurses. 2020. https://www.icn.ch/news/ more-600-nurses-die-covid-19-worldwide. Accessed 14 June 2020.

6. Kim Y. Nurses' experiences of care for patients with Middle East respiratory syndrome-coronavirus in South Korea. Am J Infect Control. 2018;46:781-7.

7. Lee AM, Wong JGWS, McAlonan GM, Cheung V, Cheung C, Sham PC, et al. Stress and psychological distress among SARS survivors 1 year after the outbreak. Can J Psychiatry Rev Can Psychiatr. 2007;52:233-40.

8. Su T-P, Lien T-C, Yang C-Y, Su YL, Wang J-H, Tsai S-L, et al. Prevalence of psychiatric morbidity and psychological adaptation of the nurses in a structured SARS caring unit during outbreak: A prospective and periodic assessment study in Taiwan. J Psychiatr Res. 2007;41:119-30.

9. Wang S, Xie L, Xu Y, Yu S, Yao B, Xiang D. Sleep disturbances among medical workers during the outbreak of COVID-2019. Occup Med. 2020;

10. Buysse DJ, Reynolds CF, Monk TH, Berman SR, Kupfer DJ. The Pittsburgh Sleep Quality Index: a new instrument for psychiatric practice and research. Psychiatry Res. 1989;28:193-213.

11. Al Maqbali M, Hughes C, Gracey J, Rankin J, Dunwoody L, Hacker E. Validation of the Pittsburgh Sleep Quality Index (PSQI) with Arabic cancer patients. Sleep Biol Rhythms. 2020;1:1-7.

12. Cohen S, Kamarck T, Mermelstein R. A global measure of perceived stress. J Health Soc Behav. 1983;24:385-96.

13. Jahrami H, BaHammam AS, AlGahtani H, Ebrahim A, Faris $\mathrm{M}$, AlEid K, et al. The examination of sleep quality for frontline healthcare workers during the outbreak of COVID-19. Sleep Breath. 2020;

14. Almadi T, Cathers I, Hamdan Mansour AM, Chow CM. An Arabic version of the Perceived Stress Scale: translation and validation study. Int J Nurs Stud. 2012;49:84-9.

15. Zigmond AS, Snaith RP. The hospital anxiety and depression scale. Acta Psychiatr Scand. 1983;67:361-70.

16. Bjelland I, Dahl AA, Haug TT, Neckelmann D. The validity of the Hospital Anxiety and Depression Scale. An updated literature review. J Psychosom Res. 2002;52:69-77.

17. Terkawi AS, Tsang S, AlKahtani GJ, Al-Mousa SH, Al Musaed S, AlZoraigi US, et al. Development and validation of Arabic version of the Hospital Anxiety and Depression Scale. Saudi J Anaesth. 2017;11:S11-8.

18. Booker LA, Magee M, Rajaratnam SMW, Sletten TL, Howard ME. Individual vulnerability to insomnia, excessive sleepiness and shift work disorder amongst healthcare shift workers A systematic review. Sleep Med Rev. 2018;41:220-33.

19. Qiu D, Yu Y, Li R-Q, Li Y-L, Xiao S-Y. Prevalence of sleep disturbances in Chinese healthcare professionals: a systematic review and meta-analysis. Sleep Med. 2020;67:258-66.

20. Lai J, Ma S, Wang Y, Cai Z, Hu J, Wei N, et al. Factors associated with mental health outcomes among health care workers exposed to coronavirus disease 2019. JAMA Netw. 2020;3:e203976-e203976.

21. Rossi R, Socci V, Pacitti F, Lorenzo GD, Marco AD, Siracusano A, et al. Mental health outcomes among frontline and second-line health care workers during the coronavirus disease 2019 (COVID19) pandemic in Italy. JAMA Netw. 2020;3:e2010185-e2010185.

22. Al Maqbali M, Al Sinani M, Al-Lenjawi B. Prevalence of stress, depression, anxiety and sleep disturbance among nurses during the COVID-19 pandemic: A systematic review and meta-analysis. J Psychosom Res. 2021;141:110343.

23. Kokou-Kpolou CK, Megalakaki O, Laimou D, Kousouri M. Insomnia during COVID-19 pandemic and lockdown: Prevalence, severity, and associated risk factors in French population. Psychiatry Res. 2020;290:113128.

24. Huang Y, Wang Y, Zeng L, Yang J, Song X, Rao W, et al. Prevalence and correlation of anxiety, insomnia and somatic symptoms in a Chinese population during the COVID-19 epidemic. Front Psychiatry. 2020. https://doi.org/10.3389/fpsyt.2020.568329/full.

25. Gualano MR, Lo Moro G, Voglino G, Bert F, Siliquini R. Effects of Covid-19 Lockdown on Mental Health and Sleep Disturbances in Italy. Int J Environ Res Public Health. 2020;17:1.

26. Ahmed AE, Al-Jahdali F, AlALwan A, Abuabat F, Salih SB, AlHarbi A, et al. Prevalence of sleep duration among Saudi adults. Saudi Med J. 2017;38:276-83.

27. Hirshkowitz M, Whiton K, Albert SM, Alessi C, Bruni O, DonCarlos L, et al. National Sleep Foundation's updated sleep duration recommendations: final report. Sleep Health J Natl Sleep Found. 2015;1:233-43.

28. Schutte-Rodin S, Broch L, Buysse D, Dorsey C, Sateia M. Clinical guideline for the evaluation and management of chronic insomnia in adults. J Clin Sleep Med JCSM Off Publ Am Acad Sleep Med. 2008;4:487-504.

29. Zhang L, Sun D, Li C, Tao M. Influencing factors for sleep quality among shift-working nurses: a cross-sectional study in china using 3-factor pittsburgh sleep quality index. Asian Nurs Res. 2016;10:277-82.

30. Zamanian Z, Nikeghbal K, Khajehnasiri F. Influence of sleep on quality of life among hospital nurses. Electron Physician. 2016;8:1811-6.

31. Sepehrmanesh Z, Mousavi G, Saberi H, Saei R. Sleep quality and related factors among the nurses of the Hospital of Kashan University of Medical Sciences. Iran Int Arch Health Sci. 2017;4:17.

32. Gold MS, Sehayek D, Gabrielli S, Zhang X, McCusker C, BenShoshan M. COVID-19 and comorbidities: a systematic review and meta-analysis. Postgrad Med. 2020;1:1-7.

33. Sanyaolu A, Okorie C, Marinkovic A, Patidar R, Younis K, Desai $\mathrm{P}$, et al. Comorbidity and its Impact on Patients with COVID-19. Sn Compr Clin Med. 2020;1:1-8.

34. Dong H, Zhang Q, Sun Z, Sang F, Xu Y. Sleep disturbances among Chinese clinical nurses in general hospitals and its influencing factors. BMC Psychiatry. 2017;17:1.

35. Guo H, Ni C, Liu C, Li J, Liu S. Perceived job stress among community nurses: a multi-center cross-sectional study. Int J Nurs Pract. 2019;25:e12703.

36. Shahrour G, Dardas LA. Acute stress disorder, coping self-efficacy, and subsequent psychological distress among nurses amid COVID-19. J Nurs Manag. 2020. https://doi.org/10.1111/jonm. 13124.

37. Yin Q, Sun Z, Liu T, Ni X, Deng X, Jia Y, et al. Posttraumatic stress symptoms of health care workers during the corona virus disease 2019. Clin Psychol Psychother. 2020;27:384-95.

38. Shechter A, Diaz F, Moise N, Anstey DE, Ye S, Agarwal S, et al. Psychological distress, coping behaviors, and preferences for support among New York healthcare workers during the COVID-19 pandemic. Gen Hosp Psychiatry. 2020;66:1-8.

39. Jackson CL, Ward JB, Johnson DA, Sims M, Wilson J, Redline $\mathrm{S}$. Concordance between self-reported and actigraphy-assessed sleep duration among African-American adults: findings from the Jackson Heart Sleep Study. Sleep. 2020;43. https://academic.oup. com/sleep/article/43/3/zsz246/5588123. Accessed 20 Sept 2020.

Publisher's Note Springer Nature remains neutral with regard to jurisdictional claims in published maps and institutional affiliations. 